\title{
Cellular therapy: shafts of light emerging for COVID-19
}

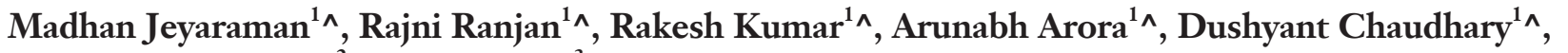 \\ Satish Shringeri Ajay ${ }^{2}$, Rashmi Jain ${ }^{3 \wedge}$
}

${ }^{1}$ Department of Orthopaedics, School of Medical Sciences \& Research, Sharda University, Greater Noida, Uttar Pradesh, India; ${ }^{2}$ Department of Orthopaedics, JJM Medical College, Davangere, Karnataka, India; ${ }^{3}$ School of Medical Sciences \& Research, Sharda University, Greater Noida, Uttar Pradesh, India

Contributions: (I) Conception and design: M Jeyaraman; (II) Administrative support: R Ranjan, R Kumar; (III) Provision of study materials or patients: A Arora, D Chaudhary; (IV) Collection and assembly of data: M Jeyaraman, R Jain, SS Ajay; (V) Data analysis and interpretation: All authors; (VI) Manuscript writing: All authors; (VII) Final approval of manuscript: All authors.

Correspondence to: Dr. Rashmi Jain. Resident, School of Medical Sciences and Research, Sharda University, Greater Noida, Uttar Pradesh 201306, India. Email: rashmijn05@gmail.com.

\begin{abstract}
The COVID-19 pandemic has presented with debilitating respiratory consequences especially more pronounced in high risk individuals. Individuals with underlying systemic diseases are more prone and vulnerable to suffer severe consequences of SARS-CoV-2 infectivity. The pathophysiological changes identified cytokine storm mechanism for out setting the series of adverse clinical conditions. Thereby, associating it with high mortality rates. This warrants urgent consideration of divergent modalities such as the cellular therapy. Cellular therapy (CT) is a new medical paradigm wherein cellular material is administered to patients for therapeutic purposes. In this regard, mesenchymal stem cells (MSCs) have yielded the most promising results among stromal vascular fraction (SVF); placental cells; natural killer (NK) cell and platelet lysate respectively. Following the administration of the CT as per preferred route, these play pivotal role in modifying the microenvironment of the lung tissue with their distinct sets of mechanism. Evidences have shown how their immunomodulatory action repairs and prevents lung injury which in turn improvise the compliance of lungs. In this review article we have discussed these emerging novel approaches and their target step serving as a ray of hope to combat severe form of COVID-19. Currently these aren't approved for preventing or treating COVID-19 cases, however clinical trials are afoot to dispense the utmost understanding in terms of efficacy and safety concerns.
\end{abstract}

Keywords: COVID-19; SARS-CoV-2; cellular therapy; mesenchymal stem cells (MSCs); natural killer (NK) cells; platelet lysate

Received: 17 May 2020; Accepted: 09 June 2020; Published: 30 June 2020.

doi: $10.21037 /$ sci-2020-022

View this article at: http://dx.doi.org/10.21037/sci-2020-022

\section{Introduction}

The saga of devastation that has currently put about a third of the world under lockdown began as 'pneumonia of unknown aetiology' in Wuhan city of China where the outbreak was at first notified on $31^{\text {st }}$ December 2019. The causative agent was soon identified as the SARS-CoV-2 (new emergent strain) and later disease was named as COVID-19 by the World Health Organization (WHO). The contagiosity continued to spread and became a Public Health Emergency of International Concern on $30^{\text {th }}$

\footnotetext{
^, ORCID: Madhan Jeyaraman, 0000-0002-9045-9493; Rajni Ranjan, 0000-0003-2324-6970; Rakesh Kumar, 0000-0003-2866-3853; Arunabh Arora, 0000-0003-0501-0665; Dushyant Chaudhary, 0000-0002-5409-8379; Satish Shringeri Ajay, 0000-0001-8905-3245; Rashmi Jain, 0000-0003-4386-6755.
} 
January 2020. On seeing the rising trend in number of cases with its rampant spread; ultimately the WHO declared it as a pandemic on $11^{\text {th }}$ March, 2020 (1). Presently, the world is battling this pandemic without any proven therapeutics. The guidelines issued by the apex body emphasises on symptom based supportive care with adequate implementation of infection preventive control measures as the mainstay $(2,3)$.

The understanding of pathogenesis of COVID-19 has outlined the key role of ACE-2 receptors for the entry of SARS-CoV-2 virus into human host. This in turn is additionally facilitated by serine proteases-TMPRSS2 $(4,5)$. Still disclosure of in-depth molecular interactions is yet to be undertaken. Following its internalization and replication; the virus alters the dynamics of human bodily functions whereby the respiratory system undergoes the major brunt of its infectivity. Moreover, its impact is more pronounced in individuals with underlying systemic disorder or any immunocompromised state or among the elderly. Studies revealed the association of storming phenomenon of cytokines with high mortality in COVID-19.

The recognition of this mechanism lends potential insight for considering the principles of regenerative sciences in the form of cellular therapy for extrapolation to COVID-19. Regenerative medicine embraces a positive future in medical conditions and henceforth all the challenges in this field of transitional research and application warrant further concrete work-up. With recent advances in molecular and tissue engineering and regeneration, the research on cellular or cell based therapy is of prime importance to the field of medical sciences. In connotation to prevailing scenario, evidences have shown mesenchymal stem cells (MSCs) to have promising results among the wide array of cell based therapy approaches.

This article renders a bird's eye-view on these emerging cellular therapies for COVID-19 enwrapped with subsets of challenges and dire need of undertaking prospective randomized controlled trials with due ethical considerations.

\section{Cellular therapy \& emerging evidences for COVID-19}

Cellular therapy is defined as the transplantation of human cells to replace or repair damaged tissue and/or cells. Some of the cells that may be used include hematopoietic stem cells (HSCs), MSCs, lymphocytes, dendritic cells, natural killer (NK) cells and pancreatic islet cells. Stem cell paves way for biological healing cascade and benefits individual without any significant morbidity.
Cellular therapy leads to the development of less invasive procedures and accelerated treatments which enhance the functional recovery of disorders. It promotes the improvement in quality, structure, function and biomechanical strength of tissue regeneration and healing process thereby offering a greater advantage in hastening recovery with decrease in morbidity and improvising the functional quality of life of the patients. The schematic representation of emerging cellular therapy for COVID-19 is shown in Figure 1.

\section{Mesenchymal stem cells (MSCs)}

MSCs are specialized adult stem cells earmarked with the capacity of multipotency. These can be derived from human or animal sources. These cells can be isolated either from fetal tissues or from adult tissues. Bone marrow has been found to harvest the efficient population of these cells (6). Moreover the multitude of cells exhibiting its characters serve as a potent source for isolation and these include adipose tissue, amniotic membrane, amniotic fluid, placenta and fetal membrane, amniotic umbilical cord lining membrane, wharton's jelly, endometrium, limb bud, dental tissues, menstrual blood, peripheral blood, skin and foreskin, salivary gland and synovial fluid $(7,8)$.

The choice of MSCs is still a debatable issue. Bone marrow derived mesenchymal stem cells (BM-MSCs) can be obtained from the iliac-crest. It should be further subjected to centrifugation (about 3,200 rpm for $15 \mathrm{~min}$ ) in order to concentrate MSCs $(9,10)$. Autologous BM-MSCs renders advantage by avoiding immunogenic reactions following administration. Adipose tissue derived mesenchymal stem cells (AD-MSCs) are abundantly found in our body and are easily accessible. But, the concentrating procedure of stem cells calls for a complex mechanistic in view of obtaining adipose tissue derived stromal vascular fraction (SVF). SVF is an aqueous fraction with combination of adipose derived stem cells, endothelial precursor cells, endothelial cells, macrophages, smooth muscle cells, lymphocytes, pericytes and pre-adipocytes (11). Interestingly, studies have found that adipose derived SVF has three times more stem cell activity in comparison to BM-MSCs (12). On the other hand, umbilical cord derived mesenchymal stem cells (UCMSCs) accounts for allogenic nature and further to deal with its associated immunological reaction expresses the need for undertaking complex procedure of lyophilisation (13). The core principle of this regenerative paradigm includes: (I) extracellular matrix that forms the ground 


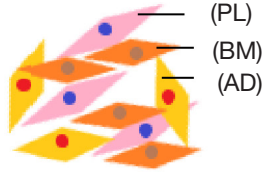

(a) Mesenchymal stem cells

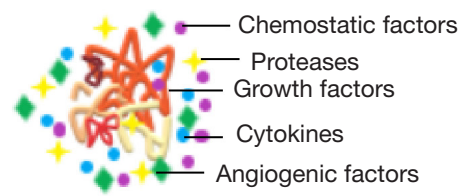

(b) Platelet lysate

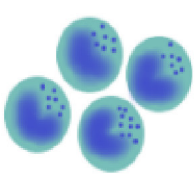

(c) Natural killer cells

Figure 1 Schematic Representation of Emerging Cellular Therapy for COVID-19. BM, bone marrow; AD, adipose tissue derived; PL, placental cells.

substance and further scaffold for stem cells to turn into desired targeted tissue; (II) growth factors being utilised in order to induce desired tissue and (III) stem cells as potent biological cells to generate desired tissue (8).

MSCs are characterized by unique capacity of selfrenewability (replication either by obligatory asymmetric or stochastic way), plasticity, potentiality of multi-lineage differentiation, homing ability and immune-regulatory properties with anti-inflammatory actions. These are readily accessible and expandable in-vitro. Interestingly these are blessed to have exceptional stable genome. However, the ethical concerns are debatable $(7,8,14,15)$.

Two pilot studies by Leng et al. $(16)\left(1 \times 10^{6}\right.$ clinical-grade MSCs per kilogram of weight intravenously) and Liang et al. (17) ( 3 doses of $5 \times 10^{7}$ hUCMSC intravenously) have been conducted in China in this context wherein they reported the beneficial role of MSCs in combating COVID-19 pneumonia respectively. A few clinical trials with UC-MSCs in China are underway and results are yet to be published [NCT04252118; NCT04273646; NCT04293692] (18-20).

\section{Platelet lysate}

The dynamics and fundamental functioning of platelets has been well documented in the medical literature. Evidences substantiates for its role in viral infection wherein these have been reported for downfall in number with the onset of viral infection (21). Such alteration involves broadspectrum mechanistic.

Clinical studies lend potential insight for directing these platelets to yield exponential release of growth factors and further rendering benefits in treating diseases. Platelets can be subjected to complex processing to form platelet rich plasma and platelet lysate. PRP holds a wide array of clinical application in treating various medical ailments. Similarly platelet lysate can also be clinically utilised. Each of these techniques is highly safe and efficacious, but differs in terms of preparation, standardization, sterility, need of activator and diluent requirement respectively.

Platelet lysate refers to acellular formulation with platelet proteins and is obtained by the lysis of platelet plasma membrane. The steps of processing involve performance of centrifugation and filtration techniques in order to remove all the cellular debris; yielding the growth factors rich content. Notably, the white cell antigens are low in amount in the procured preparation. This further minimizes the risk of immune responses. In the context of its regenerative role, the myriads of the growth factors blazes way for increasing cell proliferation and angiogenesis respectively. In a simplified manner, it releases platelet factors in supraphysiologic dose $(22,23)$.

Present studies have shown its utility as a supplement to the culture medium wherein these replaced the fetal bovine serum and further have been discussed in-vitro studies for evaluating their immune-regulatory potentiality. In lymphocyte culture, it was found that these induced T-cells to the regulatory T-phenotype (CD4+ Foxp3+) and further caused cessation of T-lymphocytes proliferation. Additionally, the cytokines related to the inflammatory profile were also inhibited (24). Platelet lysate can be used as nebulization to the lungs for treating conditions like acute lung injuries, chronic obstructive pulmonary disease (COPD) or asthma respectively. In this way, its clinical utility can plausibly be extended as an adjuvant for treating COVID-19 infection-related acute respiratory syndrome as it relegates severe inflammatory process of the respiratory tract. Moreover, it will further improve the oxygen saturation in these severe cases of COVID-19.

\section{Natural killer (NK) cells}

NK cells are the frontline players of our defence system protecting against tumorigenic cells and viral invaders. Notably, this cell constitutes as one of the main component of innate immune system and doesn't require any prestimulation for performing effector functions (25). These 
cells are characterized by large, granular, bone-marrow derived T-lymphocytes morphologically. In terms of phenotypic characterization these are defined as $\mathrm{CD}^{56+}$ and $\mathrm{CD}^{3-}$ in human population. Following $\mathrm{B}$ and T cells; these constitute as the third largest lymphocytes population wherein representing $10 \%$ of the cells among MNC (Mononuclear Cell) population. These are exclusively present in peritoneal lymph node, thymus, spleen, liver, peritoneal cavity and gravid uterus.

Their activity is well-regulated by the receptor-ligand interaction. Studies have described the biological role of these cells under tumorigenic conditions explicably and further regard it as one of the good therapeutic option for the same. Apart from this; studies are emerging wherein these cells have been extrapolated for combating conditions like asthma, autoimmune diseases and HIV-AIDS as a powerful immunological weapon.

Rapidly emerging studies have regarded NK cell to render immuno-protective role in viral infections wherein virus-induced direct cytopathic effects is believed for enacting major role in disease severity $(26,27)$. GiamarellosBourboulis et al. (2020) reported NK cell cytopenias with complex immune dysregulation in 28 severely ill COVID-19 patients (28). A few studies have reported severe immunological dysregulation in COVID-19 patients especially in individuals with co-morbidities $(29,30)$.

\section{Molecular pathogenesis of SARS-CoV-2}

SARS-CoV-2 enters into pulmonary cells by using ACE-2 receptors. Notably, the ACE- 2 membrane protein is not only confined to pulmonary cells rather it is widely distributed in cardiac, renal and hepatic tissues. Such wide expression explicably outlines the reason for severe COVID-19 infected patients to potentially suffer from multiple organ dysfunction syndrome (MODS) (31).

The COVID-19 infected patients presents with a variety of clinical manifestations like fever, non-productive cough, shortness of breath, myalgia, lymphocytopenia, anosmia, dysgeusia. The mechanism of COVID-19 pneumonia is seemingly very complex. The involved immunopathological alterations in COVID-19 pneumonia can be categorised into two categories and these are:

(I) Early, non-severe stage. During this phase the host adaptive immunity plays pivotal role in mounting a response that attempts for elimination of virus and further prevents the progression of the disease.

(II) Severe, later stage. This phase is marked by release of cytokines and chemokines respectively. These cytokines are exponentially released and blaze way for cytokine storm phenomenon resulting into severe acute respiratory distress syndrome (ARDS).

The molecular pathogenesis of SARS-CoV-2 at cellular level is shown in Figure 2. Massive endothelial and epithelial damage accompanied by vascular leakage occurs under the initial phase of viral replication. This in turn triggers the excessive production of pro-inflammatory cytokines (IFN- $\alpha$, IFN $\gamma$, IL-1 $\beta$, IL-6, IL-12, IL-8, IL-33, TNF- $\alpha$, TGF- $\beta$ ). The produced cytokines initiates 'cytokine storm' mechanism and sets off for tissue damage in an extensive manner. The major player recognised to promote this phenomenon is interleukin 6 (IL-6). It has been found that IL-6 plays significant role in acquired immune response and thereby stimulating antibody production respectively. In addition to this; other factors have been found to play equivalent role in cytokine storm and these include: multiple pro- inflammatory cytokines including IFN- $\alpha$, IFN- $\gamma$ and IL- $1 \beta$.

The cytokine storm results into ARDS and multiple organ failure and ultimately causing mortality in severe cases of COVID-19. In fact, the fatal cases of COVID-19 infections, warrants mechanical ventilation due to pronounced respiratory distress. The reported pathological findings from the lungs of severe COVID-19 patients revealed bilateral diffuse alveolar damage having cellular fibromyxoid exudations (4). This aggressive inflammatory response of SARS-CoV-2 can be attributed to its rapid viral replication, viral infection induced ACE-2 down regulation and cellular damage $(32,33)$. With respect to this background, the potential treatment targets may focus on blockage of IL-6, IL-1 and TNF for offering benefits to COVID-19 patients.

\section{Cellular therapy: target action in COVID-19}

The target actions of CT in COVID-19 has been depicted in Figure 3.

\section{MSCs}

As discussed in pathogenesis; the uncontrolled release of cytokines (IFN- $\alpha \& \gamma$, IL- $1 \beta,-6,-12,-8 \&-33$, TNF- $\alpha$, TGF- $\beta$ ) and chemokines (CCL-2, $-3 \&-5$, CXCL-8 \& -9, CXCL-10 etc) culminates into systemic manifestation causing oedema, air exchange dysfunction, ARDS, acute cardiac injury and secondary infections and may lead to 


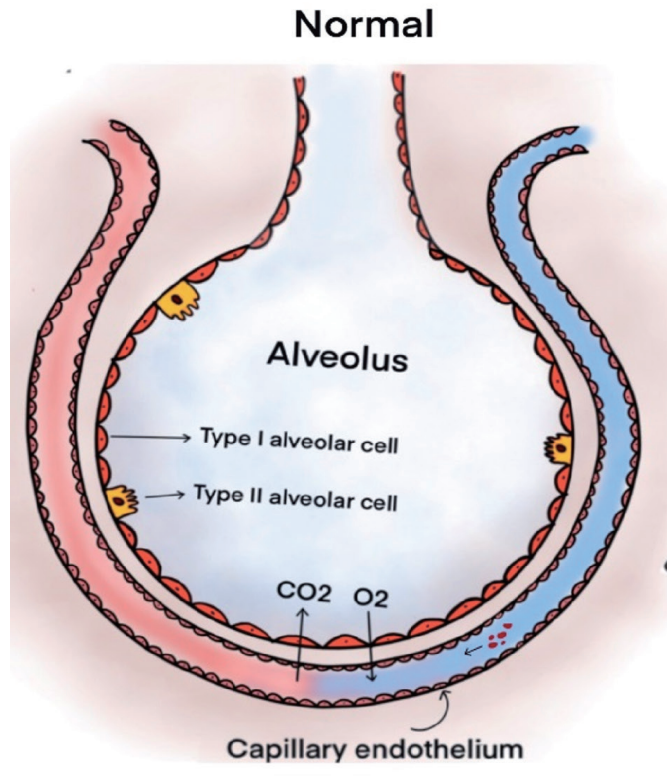

Normal gas exchange

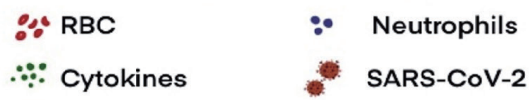

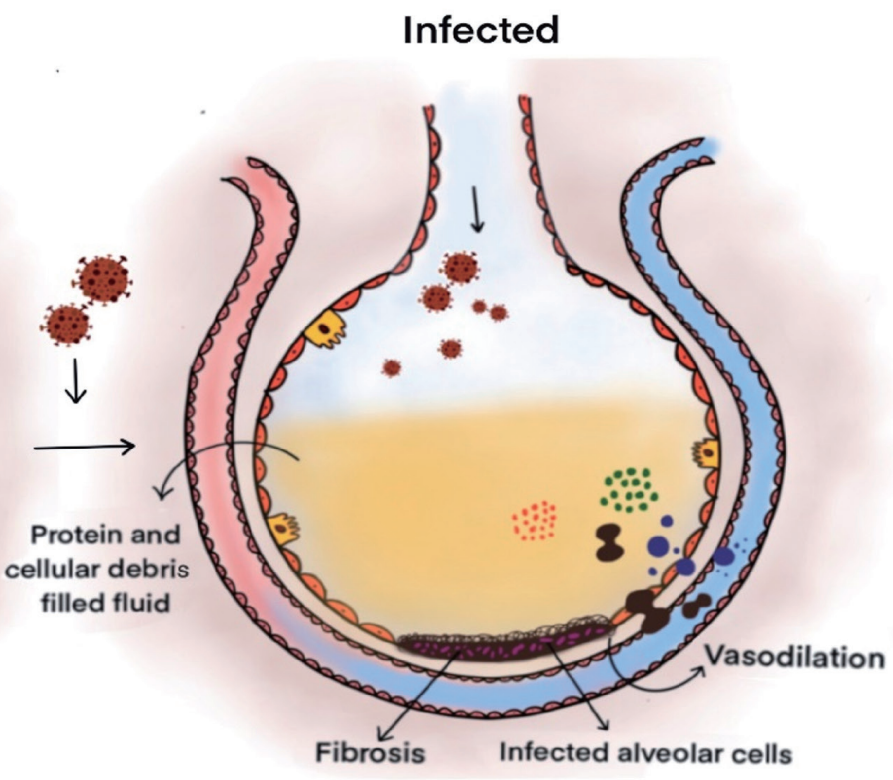

Impaired gas exchange

Figure 2 Pathophysiological Alterations of SARS-CoV-2 at Cellular Level.

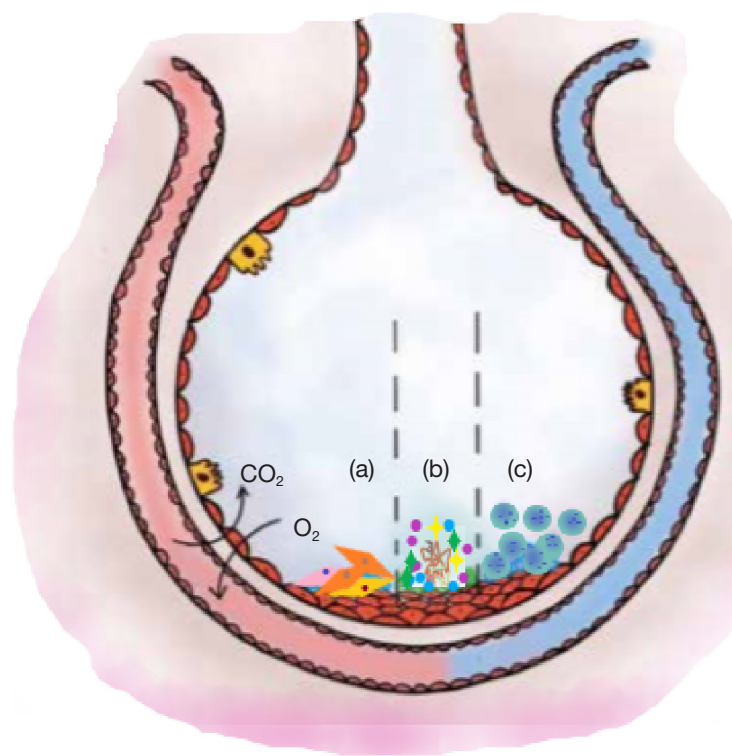

(a) MSC's [BM;AD;PL]

(b) Platelet lysate

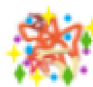

(c) NK-Cell

Figure 3 Intervention with cellular therapy (CT) in COVID-19. (a) MSCs (BM; AD; PC): immune to SARS-CoV-2; immunomodulatory; attenuates cytokine storm \& reparative function. (b) platelet lysate: supra-physiological release of growth factors; blockage of IL-6, IL-1 \& TNF- $\alpha$ \& cellular regeneration. (c) Natural killer (NK) cell: pivotal role in innate immunity; $\uparrow$ INF- $\gamma$ production; direct cytolysis of target cells \& suppression of viral replication. 
Table 1 Immuno-modulatory action of Mesenchymal Stem Cells in COVID-19 (16)

\begin{tabular}{ll}
\hline Pathophysiological changes in COVID-19 & Immuno-modulatory action following MSC Intervention \\
\hline Pulmonary lesions due to inflammation & $\begin{array}{l}\text { Improvises pulmonary fibrosis and lung function by protective role in } \\
\text { alveolar epithelium }\end{array}$ \\
$\begin{array}{l}\text { Transaminitis due to onset of multiple organ dysfunction } \\
\text { syndrome (MODS) }\end{array}$ & $\begin{array}{l}\text { Improvises micro-environmental organization and thereby promotes } \\
\text { endogenous repair in cellular/tissue organization }\end{array}$ \\
$\begin{array}{l}\text { Depletion of immune cells } \\
\begin{array}{l}\text { Inducing cytokine storm culminating into uncontrolled release of } \\
\text { cytokines and chemokines }\end{array}\end{array}$ & $\begin{array}{l}\text { Functionality of immune subsets undergoes re-organization } \\
\text { Regulates inflammatory response; inhibits T \& B lymphocytes; }\end{array}$ \\
\hline
\end{tabular}

death. The studies have demonstrated a key role of MSCs to prevent this avalanching situation $(4,29)$.

The immuno-modulation and differentiation are the two mechanisms by which MSC's can perquisite COVID-19 patients. MSC lacks key entry points and hence is naturally immune to SARS-CoV-2 (16). These regulate inflammatory response, offers regeneration and repair of endogenous tissue with no or minimal side-effects. This is how MSC's contribute in maintaining the functionality of alveolar microenvironment (34).

Leng et al. (2020), in his study discussed the immunomodulatory role MSC's and a brief account is being presented underneath in Table 1. In this manner it can enhance the function of pulmonary system, curb down pneumonia and thereby decreased associated morbidity and mortality in COVID-19 patients (16).

\section{Platelet lysate}

The role of platelets and its interplay in viral infection have been substantiated. Interestingly the thrombotic attribute of the platelets paves way for containing the invasive microbes and further its immunological interaction accounts for the clearance of microbe. Platelets possess proinflammatory cytokines facilitating inflammatory immunomodulation (35). There is a complex participation of innate and adaptive immunological aspect of platelets for clearing off micro-organisms. Researches have documented the role of platelets in defending against viral infections and this involve specific receptor-ligand interaction respectively (36). This interaction is described as ambivalent wherein platelets are activated to eliminate virus laden platelet and facilitate viral load clearance (37).

It has been found that these platelets get activated either by direct or indirect stimuli and undergoes degranulation. These further release myriads of growth factors and biomolecules which in turn participate in mediating host defensive mechanisms. In this context, a novel biomolecule called kinocidin imparts immuno-modulatory effects like in HIV-1, this platelet factor 4 (PF-4/CXCL-4) has been reported as the most potent kinocidin $(38,39)$. CCL-5 has been documented to be involved in viral lung and this has been substantiated in influenza A viral infection in mice wherein it provides signalling (anti-apoptotic) for macrophages (40).

Platelet lysate likewise platelets may emerge as a key player for viral lysis. The process of producing the platelet lysate yields a rich content of growth factors with low amount of white cell antigens. This in turn may trigger immune responses. With provision of supraphysiologic doses of platelet factors, the platelet lysate might lend a beacon of hope in cellular regeneration by enhancing the proliferation of cell and angiogenesis. This attribute can be further explored for serving as an adjuvant in COVID-19 patients.

\section{NK cells}

NK cells have been found to play crucial role in immune defence against viral infections and cancerous conditions due to their activity of cytolysis and chemokines production (41-44). Notably, these are involved in production of IFN- $\gamma$ upon recognizing certain molecular cues on certain target cells in response to inflammation or may directly execute cytolytic action on those target cells for suppressing virus replication (45).

Emerging evidences have shown that the total number of NK and $\mathrm{CD}^{+} \mathrm{T}$ cells were enormously decreased in COVID-19 patients. Further the function of NK and $\mathrm{CD} 8^{+} \mathrm{T}$ cells were found to embrace an inverse relation with expression of NKG2A in these patients. Similarly it was noted that the patients convalescing following therapy had restoration in the number of $\mathrm{NK}$ and $\mathrm{CD}^{+} \mathrm{T}$ cells 
along with decreased NKG2A expression respectively (42). It can be inferred that there is an association between the functional exhaustion of cytotoxic lymphocytes and SARS$\mathrm{CoV}-2$ infection. Moreover, these findings were evident in severely -ill SARS-CoV-2 infected patients.

The interplay of natural killer cells in viral infections magnifies their potential role in exhibiting innate immune response; enhancing IFN- $\gamma$ production; direct cytolysis of target cells and viral replication suppression. This outlines the plausible role of NK cell in COVID-19 which warrants further work-up and exploration of the same.

\section{Discussion}

The functional outcome of cellular therapy depends on the quality and quantity of cells obtained, separated and reinfused into the patient. The separation of cells and cellular products remain a question of debate in terms of centrifugation technique and duration. Various clinical trials across the globe have not validated the desired dosage of cells and route of administration (local infiltration, intravenous or inhalation) required to treat the disease. The follow-up timing and parameters to be analysed remains a major concern. The next challenge in cellular therapy is the type of cellular transplant either autologous or allogenic cells. Autologous cells carry zero immunological concern, zero risk for disease transmission and simpler technique to separate the cells. On the contrary, allogenic cells carry a definite risk for disease transmission \& immunological concern and require a complex technique for separation and storing of cells for their future use.

Till date, MSC's have turned out to be the most promising cellular therapy for COVID-19. The versatile characterization has been explicably discussed above. In a few pilot studies which have been conducted in China; none reported any side-effects of its administration. However, the standardization of dose and associated safety issues warrants undertaking prospective randomized controlled trials. On the other hand, platelet lysate and NK cell therapy may equally serve as other modalities for subjugating SARS-CoV-2 infection. All of them can be regarded as a beacon of hope especially for treating severe cases of COVID-19; provided efficacy and safety issues are addressed compassionately at the earliest.

\section{MSCs}

MSCs are ubiquitous in nature and have the advantages of self-renewal, plasticity and differentiation capacities (8). MSCs possess anti-microbial, anti-inflammatory and anti-tumorigenic potential (11). MSCs can be retrieved from bone marrow, umbilical cord, placental cells and adipose tissue (14). Here the challenges are complexly natured in terms of cell separation from adipose cells, limited availability and allogenicity of placental MSCs \& umbilical cord MSCs and quality \& quantity of cells to be transplanted $(15,34)$.

\section{Platelet lysate}

Platelets have bioactive molecules which induce the quiescent cells to perform the target effects if platelets were used in the form of platelet rich plasma. The next generation use of platelet is platelet lysate derived from ruptured membrane of platelet and thereafter these procured bioactive molecules are concentrated with the help of lyophilisation in order to produce powdered form (21). The challenge here is the technique of lyophilisation and immunogenicity $(22,37)$. The advantage in platelet lysate is the quantification of bioactive molecules present in it (46). However, it's a long way to go for validating the dose and administration techniques in various diseases.

\section{NK cells}

NK cells play a role in anti-viral and tumour immunology (25). The virus infected cells attach to NKG2D receptor. NK cells get activated and secrete antimicrobial \& immunoregulatory cytokines and finally kill the virus infected cell (27). The challenge with identification and separation of NK cells are the requirement of IHC flow cytometry, complex process of NK cell separation and quality \& quantity of cells to be infused to treat the diseases (42). According to literatures available globally, only a few connotations discuss the utility of NK cells. The molecular research has to be directed toward NK cells to explore the clinical utility and simplify the process of procurement for treating the disease pathology.

\section{Ethical concern with cellular therapy}

Food and Drug Administration guidelines, defined cultured cells as "minimally" and "more than minimally" manipulated which describe procedures "that might alter the biological features of the cells" (47). FDA has established guidelines for human cellular and tissue based therapies 
or products (HCT/Ps) under Section 351 (Regulation of drugs and/or biological products) and Section 361 (HCT/ Ps are non-subjective to any pre and post market review requirements) (47).

FDA defines minimal manipulation of cells/tissues as processing of cells/tissues that does not alter biological characteristics of cells/tissues of interest. According to FDA Section 361, Part 1271, the criteria for minimal manipulation of HCTPs include (I) HCT/P is minimally manipulated; (II) HCT/P is intended for homologous use only; (III) the manufacture of HCT/P should not involve combination of cells or tissues with another article, except for water, sterilizing or storage agents and (IV) either HCT/ $\mathrm{P}$ does not have systemic effect and independent upon the metabolic activity of living cells for its primary function or have systemic effect and dependent upon the metabolic activity of living cells for its primary function and is for autologous use or allogenic use in $1^{\text {st }}$ or $2^{\text {nd }}$ degree relative or for reproductive use (48).

\section{Conclusions}

The need of the hour urges for introspecting all the plausible options for combatting SARS-CoV-2 infection. In this connotation, cell based therapy may potentially emerge as a relatively safer modality to curb down avalanching immunological response as evident from the severe spectrum of COVID-19. Among these, MSCs are extensively explored, yet lacks standardized universal protocol for its administration. At the same time, it is equally significant to plan for understanding the detail mechanistic of platelet lysate and NK cell therapy in correlation to COVID-19. Prospective randomized controlled trials with due ethical consideration are much needed to adduce strong evidences in this regard.

\section{Acknowledgments}

We thank Dr. Arun Gulati, Senior Resident of Orthopaedics, Kalpana Chawla Government Medical College, Karnal, Haryana, India for literature search regarding COVID-19. All the authors have equally contributed in framing and reviewing the manuscript.

Funding: None.

\section{Footnote}

Conflicts of Interest: All authors have completed the ICMJE uniform disclosure form (available at http://dx.doi. org/10.21037/sci-2020-022). The authors have no conflicts of interest to declare.

Ethical Statement: The authors are accountable for all aspects of the work in ensuring that questions related to the accuracy or integrity of any part of the work are appropriately investigated and resolved.

Open Access Statement: This is an Open Access article distributed in accordance with the Creative Commons Attribution-NonCommercial-NoDerivs 4.0 International License (CC BY-NC-ND 4.0), which permits the noncommercial replication and distribution of the article with the strict proviso that no changes or edits are made and the original work is properly cited (including links to both the formal publication through the relevant DOI and the license). See: https://creativecommons.org/licenses/by-nc-nd/4.0/.

\section{References}

1. World health Organisation. Novel coronavirus (2019$\mathrm{nCoV}) 2020$.

2. World Health Organization. Clinical management of severe acute respiratory infection (SARI) when COVID-19 disease is suspected: interim guidance, 13 March 2020. [Cited: 6th May, 2020]. Available online: https://apps.who. int/iris/handle/10665/331446

3. Centers for Disease Control and Prevention. Corona virus disease 2019 (COVID-19). Interim Clinical Guidance for Management of Patients with Confirmed Coronavirus Disease (COVID-19). Updated June 2, 2020. [Cited: 2nd June, 2020]. Available online: https://www. cdc.gov/coronavirus/2019-ncov/hcp/clinical-guidancemanagement-patients.html

4. Li X, Geng M, Peng Y, et al. Molecular immune pathogenesis and diagnosis of COVID-19. J Pharm Anal 2020;10:102-8.

5. Chen Y, Liu Q, Guo D. Emerging coronaviruses: Genome structure, replication and pathogenesis. J Med Virol 2020;92:418-23.

6. Pittenger MF, Mackay AM, Beck SC, et al. Multilineage potential of adult human mesenchymal stem cells. Science 1999;284:143-7.

7. Ullah I, Subbarao RB, Rho GJ. Human mesenchymal stem cells - current trends and future prospective. Biosci Rep 2015;35:e00191.

8. Ramesh R, Jeyaraman M, Chaudhari K, et al. 
Mesenchymal Stem Cells - A Boon to Orthopedics. Open J Regen Med 2018;7:19-27.

9. Chahla J, Mannava S, Cinque ME, et al. Bone Marrow Aspirate Concentrate Harvesting and Processing Technique. Arthrosc Tech 2017;6:e441-5.

10. Sakai S, Mishima H, Ishii T, et al. Concentration of bone marrow aspirate for osteogenic repair using simple centrifugal methods. Acta Orthop 2008;79:445-8.

11. Bora P, Majumdar AS. Adipose tissue-derived stromal vascular fraction in regenerative medicine: a brief review on biology and translation. Stem Cell Res Ther 2017;8:145.

12. Han S, Sun HM, Hwang KC, et al. Adipose-Derived Stromal Vascular Fraction Cells: Update on Clinical Utility and Efficacy. Crit Rev Eukaryot Gene Expr 2015;25:145-52.

13. Nagamura-Inoue T, He H. Umbilical cord-derived mesenchymal stem cells: Their advantages and potential clinical utility. World J Stem Cells 2014;6:195-202.

14. Wei X, Yang X, Han ZP, et al. Mesenchymal stem cells: a new trend for cell therapy. Acta Pharmacol. Sin 2013;34:747-54.

15. Wagner W, Wein F, Seckinger A, et al. Comparative characteristics of mesenchymal stem cells from human bone marrow, adipose tissue, and umbilical cord blood. Exp. Hematol 2005;33:1402-16.

16. Leng Z, Zhu R, Hou W, et al. Transplantation of ACE2mesenchymal stem cells improves the outcome of patients with COVID-19 pneumonia. Aging Dis 2020;11:216-28.

17. Liang B, Chen J, Li T, et al. Clinical remission of a critically ill COVID-19 patient treated by human umbilical cord mesenchymal stem cells 2020. [ChinaXiv:202002.00084].

18. ClinicalTrials.gov. Mesenchymal Stem Cell Treatment for Pneumonia Patients Infected With COVID-19. Accessed date 04/01/2020. Available online: https://clinicaltrials. gov/ct2/show/NCT04252118

19. ClinicalTrials.gov. Study of Human Umbilical Cord Mesenchymal Stem Cells in the Treatment of Severe COVID-19. Accessed date 04/01/2020. Available online: https://clinicaltrials.gov/ct2/show/NCT04273646

20. ClinicalTrials.gov. Therapy for Pneumonia Patients iInfected by 2019 Novel Coronavirus. Accessed date 04/01/2020. Available online: https://clinicaltrials.gov/ct2/ show/NCT04293692

21. Speth C, Löffler J, Krappmann S, et al. Platelets as immune cells in infectious diseases. Future Microbiol 2013;8:1431-51.
22. Burnouf T, Strunk D, Koh MBC, et al. Human platelet lysate: Replacing fetal bovine serum as a gold standard for human cell propagation? Biomaterials 2016;76:371-87.

23. Patent:20190134252. Dressings Comprising Platelet Lysate 2019. Available online: http://www. freepatentsonline.com/y2019/0134252.html

24. Lee YL, Lee LW, Su CY, et al. Virally inactivated human platelet concentrate lysate induces regulatory $T$ cells and immunosuppressive effect in a murine asthma model. Transfusion 2013;53:1918-28.

25. Smyth MJ, Hayakawa Y, Takeda K, et al. New aspects of natural-killer-cell surveillance and therapy of cancer. Nat Rev Cancer 2002;2:850-61.

26. Min CK, Cheon S, Ha NY, et al. Comparative and kinetic analysis of viral shedding and immunological responses in MERS patients representing a broad spectrum of disease severity. Sci Rep 2016;6:25359.

27. Channappanavar R, Perlman S. Pathogenic human coronavirus infections: causes and consequences of cytokine storm and immunopathology. Semin Immunopathol 2017;39:529-39.

28. Giamarellos-Bourboulis EJ, Netea MG, Rovina N, et al. Complex Immune Dysregulation in COVID-19 Patients with Severe Respiratory Failure. Cell Host Microbe 2020;27:992-1000.e3.

29. Huang C, Wang Y, Li X, et al. Clinical features of patients infected with 2019 novel coronavirus in Wuhan, China. Lancet 2020;395:497-506.

30. Xu Z, Shi L, Wang Y, et al. Pathological findings of COVID-19 associated with acute respiratory distress syndrome. Lancet Respir. Med 2020;8:420-2.

31. Qi F, Qian S, Zhang S, et al. Single cell RNA sequencing of 13 human tissues identify cell types and receptors of human coronaviruses. Biochem Biophys Res Commun 2020;526:135-40.

32. Fu Y, Cheng Y, Wu Y. Understanding SARS-CoV-2mediated inflammatory responses: From mechanisms to potential therapeutic tools. Virol Sin 2020. [Epub ahead of print].

33. Hoffmann M, Kleine-Weber H, Krüger N, et al. The novel coronavirus 2019 (2019-nCoV) uses the SARScoronavirus receptor ACE2 and the cellular protease TMPRSS2 for entry into target cells, bioRxiv. doi: 10.1101/2020.01.31.929042.

34. Jeyaraman M, Somasundaram R, Anudeep TC, et al. Mesenchymal Stem Cells (MSCs) as a Novel Therapeutic Option for nCOVID-19-A Review. Open J Regene Med 2020;9:20-35. 
35. H. Loppnow, R. Bil, S. Hirt et al. Platelet-derived interleukin-1 induces cytokine production, but not proliferation of human vascular smooth muscle cells. Blood.1998;91:134-41.

36. Assinger A. Platelets and infection - an emerging role of platelets in viral infection. Front Immunol 2014;5:649.

37. Flaujac C, Boukour S, Cramer-Borde E. Platelets and viruses: an ambivalent relationship. Cell. Mol. Life Sci 2010;67:545-56.

38. Yeaman MR. Platelets: at the nexus of antimicrobial defence. Nat Rev Microbiol 2014;12:426-37.

39. Solomon Tsegaye T, Gnirß K, Rahe-Meyer N, et al. Platelet activation suppresses HIV-1 infection of T cells. Retrovirology 2013;10:48.

40. Tyner JW, Uchida O, Kajiwara N, et al. CCL5- CCR5 interaction provides antiapoptotic signals for macrophage survival during viral infection. Nat Med 2005;11:1180-7.

41. Vivier E, Tomasello E, Baratin M, et al. Functions of natural killer cells. Nat Immunol 2008;9:503-10.

42. Vivier E, Ugolini S, Blaise D, et al. Targeting natural killer cells and natural killer T cells in cancer. Nat Rev Immunol

doi: $10.21037 /$ sci-2020-022

Cite this article as: Jeyaraman M, Ranjan R, Kumar R, Arora A, Chaudhary D, Ajay SS, Jain R. Cellular therapy: shafts of light emerging for COVID-19. Stem Cell Investig 2020;7:11.
2012;12:239-52.

43. Sun JC, Lanier LL. NK cell development, homeostasis and function: parallels with CD8 T cells. Nat Rev Immunol 2011;11:645-57.

44. Lanier LL. Evolutionary struggles between NK cells and viruses. Nat Rev Immunol 2008;8:259-68.

45. Biron CA, Nguyen KB, Pien GC, et al. Natural killer cells in antiviral defense: function and regulation by innate cytokines. Annu Rev Immunol 1999;17:189-220.

46. Jeyaraman M, Ramesh R, Prajwal GS. The efficacy of autologous platelet rich plasma vs homologous platelet lysate in patients with early knee osteoarthritis. IP Int J Orthop Rheumatol 2018;4:47-53.

47. M. L. Torre, E. Lucarelli, S. Guidi, et al. Ex vivo expanded mesenchymal stromal cell minimal quality requirements for clinical application. Stem Cells and Development 2015;24:677-85.

48. Deasy BM, Anderson JE, Zelina Z. Regulatory Issues in the Therapeutic Use of Stem Cells. In: Andrades JA. editor. Regenerative Medicine and Tissue Engineering. Intech Open, 2013. 